\title{
Total hip arthroplasty versus resurfacing arthroplasty in the treatment of patients with arthritis of the hip joint: single centre, parallel group, assessor blinded, randomised controlled trial
}

\author{
(c) $\underset{1}{(1)(8)}$ OPEN ACCESS
}

Matthew L Costa professor of trauma and orthopaedic surgery ${ }^{1}$, Juul Achten senior research fellow ${ }^{2}$, Nicholas R Parsons trial statistician ${ }^{2}$, Richard P Edlin senior lecturer in health economics ${ }^{3}$, Pedro Foguet consultant orthopaedic surgeon ${ }^{4}$, Udai Prakash consultant orthopaedic surgeon ${ }^{4}$, Damian R Griffin professor of trauma and orthopaedic surgery ${ }^{2}$, Young Adult Hip Arthroplasty team

${ }^{1}$ Warwick Clinical Trials Unit, Division of Health Sciences, University of Warwick, Coventry CV4 7AL, UK; ${ }^{2}$ Division of Health Sciences, Warwick Medical School, University of Warwick; ${ }^{3}$ Health Systems, School of Population Health, Faculty of Medical and Health Sciences, University of Auckland, Auckland, New Zealand; ${ }^{4}$ University Hospitals Coventry and Warwickshire NHS trust, Coventry

\begin{abstract}
Objectives To compare the clinical and cost effectiveness of total hip arthroplasty with resurfacing arthroplasty in patients with severe arthritis of the hip.

Design Single centre, two arm, parallel group, assessor blinded, randomised controlled trial with 1:1 treatment allocation.

Setting One large teaching hospital in the United Kingdom.

Participants 126 patients older than 18 years with severe arthritis of the hip joint, suitable for resurfacing arthroplasty of the hip. Patients were excluded if they were considered to be unable to adhere to trial procedures or complete questionnaires.
\end{abstract}

Interventions Total hip arthroplasty (replacement of entire femoral head and neck); hip resurfacing arthroplasty (replacement of the articular surface of femoral head only, femoral neck remains intact). Both procedures replaced the articular surface of the acetabulum.

Main outcome measures Hip function at 12 months after surgery, assessed using the Oxford hip score and Harris hip score. Secondary outcomes were quality of life, disability rating, physical activity level, complications, and cost effectiveness.

Results 60 patients were randomly assigned to hip resurfacing arthroplasty and 66 to total hip arthroplasty. Intention to treat analysis showed no evidence for a difference in hip function between treatment groups at 12 months ( $t$ test, $\mathrm{P}=0.242$ and $\mathrm{P}=0.070$ for Oxford hip score and Harris hip score, respectively); $95 \%$ of follow-up data was available for analysis. Mean Oxford hip score was 40.4 (95\% confidence interval 37.9 to 42.9 ) in the resurfacing group and 38.2 ( 35.3 to 41.0 ) in the total arthroplasty group (estimated treatment effect size 2.23 (-1.52 to 5.98$)$ ).
Mean Harris hip score was 88.4 (84.4 to 92.4) in the resurfacing group and $82.3(77.2$ to 87.5$)$ in the total arthroplasty group $(6.04$ ( -0.51 to 12.58)). Although we saw no evidence of a difference, we cannot definitively exclude clinically meaningful differences in hip function in the short term. Overall complication rates did not differ between treatment groups $(P=0.291)$. However, we saw more wound complications in the total arthroplasty group $(P=0.056)$ and more thromboembolic events in the resurfacing group $(P=0.049)$.

Conclusions No evidence of a difference in hip function was seen in patients with severe arthritis of the hip, one year after receiving a total hip arthroplasty versus resurfacing arthroplasty. The long term effects of these interventions remain uncertain.

Trial registration Current Controlled Trials ISRCTN33354155, UKCRN 4093.

\section{Introduction}

For patients older than 65 years with severe arthritis of the hip, several implant designs for total hip arthroplasty (or replacement) have shown excellent long term results in terms of both function and value for money. ${ }^{1}$ However, in younger and more active patients, these traditional implants have a failure rate of about $50 \%$ after 25 years. ${ }^{2}$ Modern implant designs for total arthroplasty could improve on these results, ${ }^{3}$ but the search for new and more durable forms of arthroplasty continues.

In total hip arthroplasty, the patient's femoral head and neck are removed and replaced. Resurfacing arthroplasty is an alternative technique that preserves the neck of the patient's femur. The femoral head is then resurfaced with a cap rather 
than replaced. The concept of resurfacing arthroplasty has been around for many years, but early implant designs failed owing to limitations in the materials available and the accuracy of the production processes. ${ }^{4}$ However, improvements in material science and manufacturing technology (in particular, the ability to manufacture highly congruent metal bearing surfaces) led to renewed interest in hip resurfacing in the mid-1990s. Modern metal-on-metal resurfacing arthroplasty became popular in the early part of the 21 st century. Since then, tens of thousands of younger patients worldwide with severe arthritis of the hip have undergone resurfacing surgery. ${ }^{5}$

Resurfacing implants are more expensive than traditional (metal and plastic) implant designs for total arthroplasty. Resurfacing also has potential complications compared with total arthroplasty-most importantly, the risk of fracture of the femoral neck. ${ }^{6}$ However, early clinical results have shown that in selected patients, $98 \%$ of resurfacing implants were still functioning at five years, ${ }^{7}$ which is as good as the revision rates of any existing implant designs for total arthroplasty. ${ }^{1}$

Furthermore, early clinical outcomes suggested that resurfacing arthroplasty provide more physiological hip movement than total arthroplasty by preserving the patient's own proximal femoral anatomy. ${ }^{89}$ Other studies ${ }^{810}$ reported that patients undergoing resurfacing arthroplasty had increased activity levels compared with those having total hip arthroplasty and were more likely to participate in activities such as running and heavy manual labour. However, these studies were not randomised clinical trials.

Therefore, we conducted a randomised controlled trial to compare the clinical effectiveness of total hip arthroplasty with resurfacing arthroplasty in patients with severe arthritis of the hip. We also collected data for cost effectiveness (submitted for publication). The null hypothesis for this trial was that functional hip scores at one year after surgery did not differ between patients undergoing resurfacing arthroplasty and those undergoing total hip arthroplasty.

\section{Methods}

This study was a single centre, two arm, parallel group, assessor blinded, randomised controlled trial with 1:1 treatment allocation conducted in the United Kingdom. Full details of the protocol have been described previously, ${ }^{11}$ and a summary of the methodology follows below.

\section{Study population}

In this pragmatic trial, participants were eligible if they were older than 18 years of age, medically fit for an operation, and suitable for a resurfacing arthroplasty (patients who are suitable for resurfacing are also suitable for total hip arthroplasty). We excluded patients from the study if evidence indicated that they would be unable to adhere to trial procedures or complete questionnaires. To maintain strict independence between observed outcome measures, if a recruited patient needed a contralateral hip replacement during the trial period, the second hip was not included in the study.

\section{Recruitment and randomisation of participants}

Patients were recruited between May 2007 and February 2010 from hip replacement clinics at the University Hospitals Coventry and Warwickshire NHS trust, in Coventry, UK. Eligible patients gave written informed consent. Patients were randomly assigned on a 1:1 basis to receive either a total hip arthroplasty or a resurfacing arthroplasty.

Treatment allocation was determined using a computer generated, randomised number sequence and stratified by the supervising orthopaedic surgeon to balance any potential surgeon effects. After patients consented to participate in the trial, an independently administered, secure randomisation service was alerted by telephone of a new enrolment. The randomisation officer provided the surgeon's secretary with the patient's treatment allocation, thereby keeping the research associates, who consented patients and collected outcome data, blinded to the allocated treatment. The patients were informed, by letter, of their treatment allocation in the week after consenting.

\section{Interventions}

The study treatments were total hip arthroplasty and resurfacing arthroplasty. Before the operation, all patients followed the same preoperative assessment process. To ensure that the trial results could be generalised to as wide a group of patients as possible, each patient had the allocated surgery according to the preferred technique of the operating surgeon. Other perioperative interventions, such as prophylactic antibiotics and thromboprophylaxis, were the same for all patients. After the operation, all patients underwent the same standardised rehabilitation plan, including range-of-movement exercises followed by muscle strengthening exercises. Unless the operating surgeon specifically advised otherwise, all patients were fully weight bearing immediately.

In a total hip arthroplasty, the femoral head is removed along with most of the femoral neck. The femoral shaft is exposed to open up the femoral canal. The femoral component is then inserted into the canal and the articulating femoral head is placed onto the neck of the femoral component. The choice of components (cemented $v$ uncemented) and bearing surfaces was left to the discretion of the operating surgeon, as per their usual clinical practice.

In a resurfacing arthroplasty, the articular surfaces of the femoral head are removed but the neck is left in situ. The femoral component (cap) is then impacted onto the patient's own femoral neck. All resurfacing arthroplasties of the hip use metal-on-metal bearing surfaces, but the choice of surgical approach, implant size, and positioning was left to the discretion of the operating surgeon. In both forms of arthroplasty, the acetabulum is prepared and the acetabular component inserted into the socket.

\section{Outcome measurements}

\section{Primary outcomes}

The primary outcome measure was hip function, as assessed by the Oxford hip score ${ }^{12}$ and Harris hip score. ${ }^{13}$ The Oxford hip score is a validated, self administered questionnaire consisting of 12 items related to daily tasks directly affected by poor hip function. The Harris hip score is also a questionnaire on hip function that includes not only items reflecting a patient's ability to perform normal daily activities, but also objective measurements such as range-of-movement exercises. Therefore, the questionnaire for Harris hip score was partly completed by the patient and partly completed by a blinded research physiotherapist.

Previous work has shown both these hip scores to be reliable and reproducible measures of hip function after surgery. ${ }^{12} 1415$ However, the self administered Oxford hip score has much higher follow-up rates than the more widely used Harris hip 
score. ${ }^{15}$ Therefore, to provide the optimal assessment of hip function after surgery and also to allow dissemination of the trial results to as wide a potential audience as possible, we chose to use both hip scores as primary outcome measures. We collected data for these outcomes at baseline (preoperatively), and in follow-up clinics at six weeks, three months, six months, and 12 months after surgery. The 12 month follow-up was the primary endpoint for this trial.

\section{Secondary outcomes}

We collected data for four secondary outcome measures at baseline, and at three, six, and 12 month follow-up:

(1) EuroQol 5D (EQ-5D): a validated quality of life questionnaire consisting of five questions related to daily activities scored on a three point ordinal score scale. We assessed quality of life with both a visual analogue health scale rating and the combined responses to questions using published algorithms to obtain values for health related quality of life ${ }^{16}$

(2) Disability rating index: a self administered, 12 item, visual analogue scale questionnaire assessing the patient's own rating of disability ${ }^{17}$

(3) Paffenbarger physical activity questionnaire: a questionnaire that assesses weekly energy expenditure on leisure and physical activities ${ }^{18}$

(4) Any complications recorded during the course of the trial.

\section{Sample size}

To detect a change of 7 points (standard deviation 13) in the Harris hip score with a two sided 5\% significance level and $80 \%$ power, based on approximate normality of the score distribution, we needed 55 patients per group. ${ }^{15}$ The change of 7 points is the lower limit of the range ( 7 to 10 points) suggested to show a minimum clinically important difference. Similarly, a change of 5 points (9) in the Oxford hip score needed 52 patients per group, again for $80 \%$ power and $5 \%$ significance. ${ }^{19}$ If we allowed for an anticipated dropout rate of $10 \%$, the total sample size was 120 patients. We used a closed testing procedure

$\left(\right.$ Holm-Bonferroni ${ }^{20}$ ) for the analysis, and made no specific multiplicity adjustment to the significance level used in the power analysis.

\section{Statistical analysis}

The main analysis assessed differences in primary endpoints at 12 month follow-up between treatment groups using independent samples and Student $t$ tests on an intention to treat basis. The overall significance level was set to $5 \%$, with individual test levels for the primary outcomes adjusted to allow for the multiple comparisons using the method of Holm-Bonferroni. ${ }^{20}$ A prespecified subsidiary analysis used linear regression to quantify the effects of the treatment groups on each of the primary outcome measures after adjusting for both patient age and sex. Estimated treatment effects from these analyses were presented with $95 \%$ confidence intervals. We also analysed secondary outcome variables using Student $t$ tests and $\chi^{2}$ tests as appropriate, and compared total complications rates at 12 months between the two study groups using Fisher's exact test; individual test levels for these analyses were set to $5 \%$. Because the number of missing values at 12 months was small for all outcome measures, we used a complete case analysis. The patient was identified as the unit of analysis, but because all participants in the trial underwent only unilateral procedures, this unit was synonymous with the hip in the primary analyses.

\section{Results}

One hundred and seventy five patients were eligible for inclusion. ${ }^{11}$ Figure $1 \Downarrow$ shows the flow of these patients through the trial. Forty nine patients declined to take part; of 47 patients who expressed a preference, $34(72 \%)$ preferred to receive a resurfacing arthroplasty. A total of 126 patients consented to take part in the trial and underwent randomisation: 60 to resurfacing arthroplasty and 66 to total hip arthroplasty. Four patients (two in each treatment group) did not undergo hip arthroplasty surgery during the study period; three patients withdrew for personal reasons, one patient developed clinical contraindications to surgery after randomisation. However, we followed up these patients as per protocol and included their data in the intention to treat analysis. At the primary endpoint of 12 months, loss to follow-up was $5 \%$ in both groups (fig 1).

Table $1 \Downarrow$ summarises the demographic characteristics of patients at baseline, as well as the patients' hip function, quality of life, and disability rating scores before surgery. The two groups of patients were well balanced in terms of baseline characteristics and were representative of the wider population of patients undergoing resurfacing arthroplasty in the UK during this period of recruitment. One patient receiving total hip arthroplasty had a background of Perthes disease. In the resurfacing group, two patients had a background of developmental dysplasia of the hip, one had post traumatic arthritis after a previous fracture of the acetabulum, and one had a history of ankylosing spondylitis. The remaining patients in both groups had osteoarthritis of the hip as the primary diagnosis. We saw no evidence of a difference in sex distribution ( $\chi^{2}$ test; $\left.\mathrm{P}=0.984\right)$, age ( $t$ test; $\left.\mathrm{P}=0.764\right)$, or hip function ( $t$ test; Harris hip score, $\mathrm{P}=0.594$; Oxford hip score, $\mathrm{P}=0.959)$ between patients who were eligible but declined to take part and those patients who were included (data not shown).

\section{Treatment details}

Twenty surgeons performed the 122 arthroplasties in this trial. An orthopaedic consultant was recorded as the lead operating surgeon in 88 (76\%) operations, with the remaining $28(24 \%)$ being led by senior orthopaedic trainees. The proportion of consultant versus trainee surgeons was similar in the two treatment groups. All resurfacing arthroplasties were performed with large diameter metal-on-metal bearings. Of the total hip arthroplasties, 29 (44\%) implants had ceramic-on-ceramic bearings, 27 (41\%) metal-on-metal, three (5\%)

ceramic-on-polyethylene, and five ( $8 \%$ ) metal-on-polyethylene. Three femoral components were cemented and five acetabular components were cemented; all other components were implanted uncemented.

\section{Primary outcome}

Intention to treat analysis showed that hip function did not differ between treatment groups at 12 months after surgery $(t$ test; Oxford hip score, $\mathrm{P}=0.242$; Harris hip score, $\mathrm{P}=0.070$; table $2 \Downarrow$ ). Temporal trends for the primary outcome measures (fig $2 \Downarrow$ ) showed that both functional scores improved from baseline to six months after surgery and were reasonably stable from this time point to the trial endpoint at 12 months. Adjusting for age and sex in a regression analysis made no qualitative difference to the conclusions (Oxford hip score, $\mathrm{P}=0.208$; Harris hip score, $\mathrm{P}=0.074)$. Similarly, an analysis based on per protocol treatment allocation also showed no evidence for treatment group 
differences in both an unadjusted and adjusted analysis (Oxford hip score, $\mathrm{P}=0.574$; Harris hip score, $\mathrm{P}=0.179$ ).

Although no evidence indicated significant treatment effects on the primary outcome measures, estimated $95 \%$ confidence intervals for treatments effects at 12 months after operation were relatively wide (Harris hip score, 6.04 ( -0.51 to 12.58 ); Oxford hip score, 2.23 ( -1.52 to 5.98)). Thus, a clinically important effect cannot be definitively ruled out. ${ }^{11}$

\section{Secondary outcomes}

We saw no evidence of treatment group effects for any secondary outcome measures at 12 months. Table 2 shows the analysis results for the EQ-5D (two sample $t$ test, $\mathrm{P}=0.173$ ), EQ-5D visual analogue health scale $(\mathrm{P}=0.580)$, disability rating index $(\mathrm{P}=0.111)$, and results from the Paffenbarger physical activity questionnaire $(\mathrm{P}=0.708)$. Overall complications rates did not differ between treatment groups (Fisher's exact test, $\mathrm{P}=0.291$; table $3 \Downarrow$ ). However, we saw more superficial wound complications in the total arthroplasty group $(\mathrm{P}=0.056)$ and more thromboembolic events in the resurfacing arthroplasty group $(\mathrm{P}=0.049)$.

\section{Discussion}

\section{Summary of results}

This randomised clinical trial found no evidence of a difference in hip function between patients having total hip arthroplasty versus resurfacing arthroplasty for severe arthritis of the hip joint. However, we cannot definitively rule out clinically meaningful differences, and the long term outcome of resurfacing arthroplasty remains uncertain.

We also saw no evidence of a difference in terms of disability rating or activity levels in the first year after surgery. The overall rate of complications in the two groups was similar, but we found evidence of more superficial wound complications in the total arthroplasty group and more thromboembolic events in the resurfacing arthroplasty group; however, the number of events was small. We could not see an obvious reason for the difference in the number of infections; if anything, the soft tissue dissection (and hence tissue damage) needed for total hip arthroplasty is less than that needed for resurfacing arthroplasty. The difference in the number of deep vein thromboses could have been due to the increased rotation of the hip needed to expose the femoral head in resurfacing arthroplasty. This movement could have occluded the femoral vein, although we did not investigate this possibility in this study.

\section{Comparison with other studies}

Only a few randomised trials have compared total hip arthroplasty with the resurfacing technique. The first studies focused on the technical aspects of the operation, such as the position of the implants or the amount of bone removed during the resurfacing procedure. ${ }^{21} 22$ More recently, two Canadian trials compared clinical outcomes for resurfacing arthroplasty with a specific type of total hip arthroplasty-large diameter, metal-on-metal total hip arthroplasty. ${ }^{23} 24$

Garbuz and colleagues' study ${ }^{18}$ of 107 patients showed no evidence of a difference in quality of life between the two treatment groups. However, the authors were concerned about the high levels of metal debris created by the large metal hip bearings used in this trial, with the levels of metal ions being higher in the group receiving total hip arthroplasty than the group receiving resurfacing arthroplasty. In their trial of 48 patients, Lavigne and colleagues ${ }^{19}$ found no evidence of a difference between treatment groups in their primary outcome measure, gait speed. However, they too subsequently raised concerns about the possible adverse effects of large diameter, metal-on-metal total hip arthroplasty in this group of patients. ${ }^{25}$

In both trials, the investigators chose to use the same bearing surfaces in both treatment groups, that is, large diameter, metal-on-metal bearings. However, subsequent, widely reported concerns regarding the adverse effects of metal debris from these bearing surfaces have made it difficult to interpret these trials; particularly because the functional deficits associated with adverse reactions to metal debris seemed to be greater in one group (total arthroplasty) than the other (resurfacing arthroplasty). ${ }^{26}$ Furthermore, in the UK, younger patients with severe arthritis of the hip are offered a range of bearing surfaces, including metal, polyethylene, and ceramic components. ${ }^{27}$

Therefore, the Canadian trials are not directly relevant to clinical practice in the UK. We designed the present trial to reflect this variation in the choice of total arthroplasty across the UK and, indeed, worldwide.

\section{Strengths and limitations of study}

The main strength of this trial is that it was entirely pragmatic, with a relatively large number of surgeons using different hip implants and their own preferred surgical technique. Although we recruited patients from only one centre, the large number of surgeons involved and the variety of implants used probably reflects practice in the wider surgical community. Other strengths included the use of validated, patient reported outcome tools, which were assessed by researchers who were blinded to the type of hip arthroplasty, and the very high levels of complete follow-up data at the primary endpoint (95\%).

The key limitation of this trial was that the patients themselves were not blinded to their type of hip arthroplasty. Patients undergoing resurfacing arthroplasty in the UK generally receive a preoperative information sheet and surgical consent form that is different from documents given to those undergoing a total hip arthroplasty. This information details the existing evidence regarding the different risk-benefit profiles of the two procedures. Therefore, in our clinical setting and after discussion with our institutional review board, we did not consider it ethical to blind the patients to their treatment allocation within the trial.

\section{Conclusions and policy implications}

How do the results of this trial inform the debate about resurfacing arthroplasty in patients with severe arthritis of the hip joint? Hip resurfacing has been widely adopted in response to perceived advantages over total hip arthroplasty. Firstly, the large diameter, metal-on-metal bearings afforded by resurfacing could reduce complications related to wear on moving surfaces. Secondly, preservation of the normal femoral anatomy in resurfacing would facilitate better hip function and higher activity levels than with total hip arthroplasty. Thirdly, preservation of the proximal femoral bone stock would make revision surgery easier in the future; revision being a distinct possibility in this younger group of patients who place high demands on their joint replacement.

In vitro studies have confirmed low rates of wear in large diameter, metal-on-metal bearing surfaces ${ }^{28}$ However, recent concerns regarding the effects of metal debris in vivo have largely superseded these mechanical considerations ${ }^{26}$ and even raised concerns regarding the wider regulation of medical devices. ${ }^{29}$ Arthroplasty registries have indicated that such in vivo effects could translate into increased revision rates in hip replacements that use large diameter, metal-on-metal bearings. ${ }^{30}$ 
This trial failed to show evidence that resurfacing arthroplasty provides improved hip function or increased activity levels, compared with total hip arthroplasty. Patients will be able use this information when deciding on which type of arthroplasty to have for their severe arthritis of the hip. However, only long term studies can determine any advantage with regard to the need for revision surgery. We will continue to review the patients in this trial over the coming years.

We thank Becky Kearney, Katie McGuinness, Helen Richmond, Phil Jones, Kate Dennison, Zoe Buckingham, Troy Douglin, and Catherine Richmond for their assistance in recruitment and data collection during the trial; Chris McCarthy, Chris Bridle, Ceri Jones, Tim Friede, and Steve Krikler for their clinical, trials, and regulatory expertise in the trial steering committee and data monitoring committee for this trial; and all the patients for their time and effort in participating in this trial.

This trial was conducted on behalf of the Young Adult Hip Arthroplasty team at the University Hospitals Coventry and Warwickshire NHS trust: Matthew Costa, Pedro Foguet, Udai Prakash, Damian Griffin, Richard King, Steve Krikler, and Gavin Pereira.

Contributors: MLC, JA, and NRP designed the study and analysed and interpreted the trial data. MLC, PF, UP, DRG managed the recruitment and follow-up of the patients. RE was responsible for the health economics analysis of the trial. MLC, JA, and NRP planned and wrote the first draft of the paper, which was subsequently revised by all authors. All authors read and approved the final manuscript. MLC is guarantor.

Funding: This study was funded by the Research for Patient Benefit scheme of the National Institute of Health Research. This trial was cosponsored by the University of Warwick and University Hospitals Coventry and Warwickshire NHS trust. This manuscript presents independent research commissioned by the National Institute of Health Research. The views expressed are those of the authors and not necessarily those of the NHS, the National Institute of Health Research, or the Department of Health.

Competing interests: All authors have completed the Unified Competing Interest form at www.icmje.org/coi_disclosure.pdf (available on request from the corresponding author) and declare: funding from the National Institute of Health Research, University of Warwick, and University Hospitals Coventry and Warwickshire NHS trust; consultant surgeons at the University Hospitals Coventry and Warwickshire NHS trust have received research project funding and provided paid educational support to meetings sponsored by manufacturers of both total hip arthroplasty and resurfacing arthroplasty implants, but not in relation to this study. Ethical approval: This study was approved by the Coventry research ethics committee (no 07/Q2802/26) on 9 May 2007. Further approval was obtained from the research and development department of the University Hospitals Coventry and Warwickshire NHS trust. This research complies with the Helsinki Declaration.

Data sharing: no additional data available.

1 Murray DW, Carr AJ, Bulstrode CJ. Which primary total hip replacement? J Bone Joint Surg Br 1995;77:520-7.

2 Wroblewski BM, Fleming PA, Siney PD. Charnley low-frictional torque arthroplasty of the hip. 20-to-30 year results. J Bone Joint Surg Br 1999;81:427-30.

3 Digas G, Karrholm J, Thanner J, Malchau H, Herberts P. The Otto Aufranc Award. Highly cross-linked polyethylene in total hip arthroplasty: randomized evaluation of penetration rate in cemented and uncemented sockets using radiostereometric analysis. Clin Orthop Relat Res 2004:429:6-16.

4 Grigoris $\mathrm{P}$, Roberts $\mathrm{P}, \mathrm{Panousis} \mathrm{K}$, Jin Z. Hip resurfacing arthroplasty: the evolution of contemporary designs. Proc Inst Mech Eng H 2006;220:95-105.

5 Australian National Joint Replacement Registry. Demographics of hip and knee arthroplasty. 2010. www.dmac.adelaide.edu.au/aoanjrr/documents/aoanjrrreport_2010. pdf.

6 Cuckler JM. The optimal metal-metal arthroplasty is still a total hip arthroplasty: in the affirmative. J Arthroplasty 2006;21:74-6.

7 Treacy RB, McBryde CW, Pynsent PB. Birmingham hip resurfacing arthroplasty. A minimum follow-up of five years. J Bone Joint Surg Br 2005;87:167-70.

8 Pollard TC, Baker RP, Eastaugh-Waring SJ, Bannister GC. Treatment of the young active patient with osteoarthritis of the hip. A five- to seven-year comparison of hybrid total hip arthroplasty and metal-on-metal resurfacing. J Bone Joint Surg Br 2006;88:592-600.

9 Lingard EA, Muthumayandi K, Holland JP. Comparison of patient-reported outcomes between hip resurfacing and total hip replacement. J Bone Joint Surg Br 2009;91:1550-4.

10 Vail TP, Mina CA, Yergler JD, Pietrobon R. Metal-on-metal hip resurfacing compares favorably with THA at 2 years followup. Clin Orthop Relat Res 2006;453:123-31.

11 Achten J, Parsons NR, Edlin RP, Griffin DR, Costa ML. A randomised controlled trial of total hip arthroplasty versus resurfacing arthroplasty in the treatment of young patients with arthritis of the hip joint. BMC Musculoskeletal Dis 2010;11:8.

12 Dawson J, Fitzpatrick R, Carr A, Murray D. Questionnaire on the perceptions of patients about total hip replacement. J Bone Joint Surg Br 1996;78:185-90.

13 Harris WH. Traumatic arthritis of the hip after dislocation and acetabular fractures: treatment by mold arthroplasty. An end-result study using a new method of result evaluation. J Bone Joint Surg Am 1969;51:737-55.

14 Soderman $\mathrm{P}$, Malchau $\mathrm{H}$. Is the Harris hip score system useful to study the outcome of total hip replacement? Clin Orthop Relat Res 2001:189-97.

15 Kalairajah Y, Azurza K, Hulme C, Molloy S, Drabu KJ. Health outcome measures in the evaluation of total hip arthroplasties-a comparison between the Harris hip score and the Oxford hip score. J Arthroplasty 2005;20:1037-41.

16 Brooks R. EuroQol: the current state of play. Health Policy 1996;37:53-72.

17 Salen BA, Spangfort EV, Nygren AL, Nordemar R. The Disability Rating Index: an instrument for the assessment of disability in clinical settings. J Clin Epidemiol 1994;47:1423-35.

18 Paffenbarger R, Wing A, Hyde RT. Physical activity as an index of heart attack risk in college alumni. Am J Epidemiol 1978;108:161-75.

19 Murray DW, Fitzpatrick R, Rogers K, Pandit H, Beard DJ, Carr AJ, et al. The use of the Oxford hip and knee scores. J Bone Joint Surg Br 2007;89:1010-4.

20 Holm S. A simple sequentially rejective multiple test procedure. Scand J Stat 1979;6:65-70

21 Loughead JM, Chesney D, Holland JP, McCaskie AW. Comparison of offset in Birmingham hip resurfacing and hybrid total hip arthroplasty. J Bone Joint Surg Br 2005;87:163-6.

22 Vendittoli PA, Lavigne M, Girard J, Roy AG. A randomised study comparing resection of acetabular bone at resurfacing and total hip replacement. J Bone Joint Surg $\mathrm{Br}$ 2006;88:997-1002

23 Garbuz DS, Tanzer M, Greidanus NV, Masri BA, Duncan CP. The John Charnley Award: metal-on-metal hip resurfacing versus large-diameter head metal-on-metal total hip arthroplasty: a randomized clinical trial. Clin Orthop Relat Res 2010;468:318-25.

24 Lavigne M, Therrien M, Nantel J, Roy A, Prince F, Vendittoli PA. The John Charnley Award: the functional outcome of hip resurfacing and large-head THA is the same: a randomized, double-blind study. Clin Orthop Relat Res 2010;468:326-36

25 Vendittoli PA, Roy A, Mottard S, Girard J, Lusignan D, Lavigne M. Metal ion release from bearing wear and corrosion with $28 \mathrm{~mm}$ and large-diameter metal-on-metal bearing articulations: a follow-up study. J Bone Joint Surg Br 2010;92:12-9.

26 Skinner J, Kay P. Commentary: metal on metal hips. BMJ 2011;342:d3009.

27 National Joint Registry for England and Wales. Prostheses used in hip, knee and ankle replacement procedures. 2010. www.njrcentre.org.uk/NjrCentre/LinkClick.aspx? fileticket=lgUspxM82lk\%3d\&tabid=86\&mid=523.

28 Smith SL, Dowson D, Goldsmith AA. The effect of femoral head diameter upon lubrication and wear of metal-on-metal total hip replacements. Proc Inst Mech Eng H 2001;215:161-70.

29 Wilmshurst $P$. The regulation of medical devices. BMJ 2011;342:d2822.

30 Australian Orthopaedic Association. Annual report hip and knee replacement. 2011. www. dmac.adelaide.edu.au/aoanjrr/documents/AnnualReports2011/Lay_Summary 2011.pdf.

31 Marchetti P, Binazzi R, Vaccari V, Girolami M, Morici F, Impallomeni C, et al. Long-term results with cementless Fitek (or Fitmore) cups. J Arthroplasty 2005;20:730-7.

32 Kalairajah Y, Azurza K, Hulme C, Molloy S, Drabu KJ. Health outcome measures in the evaluation of total hip arthroplasties-a comparison between the Harris hip score and the Oxford hip score. J Arthroplasty 2005;20:1037-41.

Accepted: 2 March 2012

\section{Cite this as: BMJ 2012;344:e2147}

This is an open-access article distributed under the terms of the Creative Commons Attribution Non-commercial License, which permits use, distribution, and reproduction in any medium, provided the original work is properly cited, the use is non commercial and is otherwise in compliance with the license. See: http://creativecommons.org/licenses/by$\mathrm{nc} / 2.0 /$ and http://creativecommons.org/licenses/by-nc/2.0/legalcode. 


\section{What is already known on this topic}

Total hip replacement is a successful treatment for older patients with severe arthritis of the hip However, in younger and more active patients, traditional hip replacements might not provide the best function and could wear out Hip resurfacing is an alternative form of replacement designed specifically to cope with the high functional demands of more active patients

\section{What this study adds}

Despite the theoretical advantages, we found no evidence that hip resurfacing provides better hip function or higher activity levels than total hip replacement in the first year after surgery

The clinical and cost effectiveness of hip resurfacing in the long term has yet to be established

\section{Tables}

Table 1| Baseline characteristics of study participants. Data are mean (standard deviation) unless indicated otherwise

\begin{tabular}{lcc} 
Characteristic & Resurfacing arthroplasty $(\mathbf{n}=60)$ & Total hip arthroplasty $(\mathbf{n}=66)$ \\
Female sex $(\mathrm{n})$ & 22 & 30 \\
\hline Age (years) & $56.3(7.3)$ & $56.6(6.6)$ \\
\hline Body mass index & $28.6(6.3)$ & $28.7(4.6)$ \\
\hline Primary diagnosis osteoarthritis $(\%)$ & 98 & 93 \\
\hline Harris hip score & $48.6(14.2)$ & $50.1(13.5)$ \\
\hline Oxford hip score & $19.1(8.0)$ & $19.6(7.8)$ \\
\hline EQ-5D score & $0.33(0.34)$ & $0.36(0.33)$ \\
\hline EQ-5D VAS score & $56.7(22.9)$ & $57.8(24.3)$ \\
\hline Disability rating index & $57.0(16.5)$ & $57.9(18.2)$ \\
\hline Paffenbarger activity $(\mathrm{mJ} /$ week) & $8.53(11.40)$ & $6.55(6.72)$ \\
\hline
\end{tabular}

VAS=visual analogue health scale. 
Table 2| Outcome data for 126 trial participants at 12 months after operation

\begin{tabular}{|c|c|c|c|}
\hline \multirow[b]{2}{*}{ Outcome measure } & \multicolumn{2}{|c|}{ Mean $(95 \% \mathrm{Cl})$} & \multirow[b]{2}{*}{ Effect $(95 \% \mathrm{Cl})$} \\
\hline & Resurfacing arthroplasty $(n=60)$ & Total hip arthroplasty $(n=66)$ & \\
\hline \multicolumn{4}{|l|}{ Primary } \\
\hline Harris hip score & 88.4 (84.4 to 92.4$)$ & 82.3 (77.2 to 87.5$)$ & $6.04(-0.51$ to 12.58$)$ \\
\hline Oxford hip score & 40.4 (37.9 to 42.9$)$ & $38.2(35.3$ to 41.0$)$ & $2.23(-1.52$ to 5.98$)$ \\
\hline \multicolumn{4}{|l|}{ Secondary } \\
\hline EQ-5D score & $0.796(0.721$ to 0.870$)$ & 0.719 (0.636 to 0.802$)$ & $0.077(-0.034$ to 0.188$)$ \\
\hline EQ-5D VAS scale & 78.2 (73.9 to 83.4 ) & 76.2 (70.8 to 81.5$)$ & $2.1(-5.3$ to 9.4$)$ \\
\hline Disability rating index & 27.7 (21.7 to 33.7 ) & 34.8 (28.4 to 41.2$)$ & $-7.1(-15.8$ to 1.6$)$ \\
\hline Paffenbarger activity ( $\mathrm{mJ} /$ week) & $15.01(10.15$ to 19.87$)$ & $13.85(10.90$ to 17.80$)$ & $1.17(-4.99$ to 7.32$)$ \\
\hline
\end{tabular}

VAS=visual analogue health scale. 
Table 3| Complications by treatment group

\begin{tabular}{|c|c|c|c|c|c|}
\hline \multirow[b]{2}{*}{ Complication } & \multicolumn{2}{|c|}{ Resurfacing arthroplasty $(n=60)$} & \multicolumn{2}{|c|}{ Total hip arthroplasty $(n=66)$} & \multirow[b]{2}{*}{$\mathrm{Pt}$} \\
\hline & No of events & Percentage $(95 \% \mathrm{Cl})$ & No of events & Percentage $(95 \% \mathrm{Cl})$ & \\
\hline Deep infection & 0 & $0.0(0.0$ to 7.5$)$ & $2^{*}$ & $3.0(0.5$ to 11.5$)$ & 0.497 \\
\hline Deep vein thrombosis & 4 & $6.7(2.2$ to 17.0$)$ & 0 & $0.0(0.0$ to 6.9$)$ & 0.049 \\
\hline Superficial wound complications & 2 & $3.3(0.6$ to 12.5$)$ & 9 & $13.6(6.8$ to 24.8$)$ & 0.057 \\
\hline Dislocation & 1 & $1.7(0.1$ to 10.1$)$ & 1 & $1.5(0.1$ to 9.3$)$ & 1.000 \\
\hline Other & 4 & $6.7(2.2$ to 17.0$)$ & 6 & $9.1(3.7$ to 19.4$)$ & 0.747 \\
\hline Total & 11 & 18.3 (9.9 to 30.9$)$ & 18 & 27.3 (17.4 to 39.8$)$ & 0.291 \\
\hline
\end{tabular}

*Both patients treated with surgical debridement but neither patient needed revision of the components. †Fisher's exact test. 


\section{Figures}

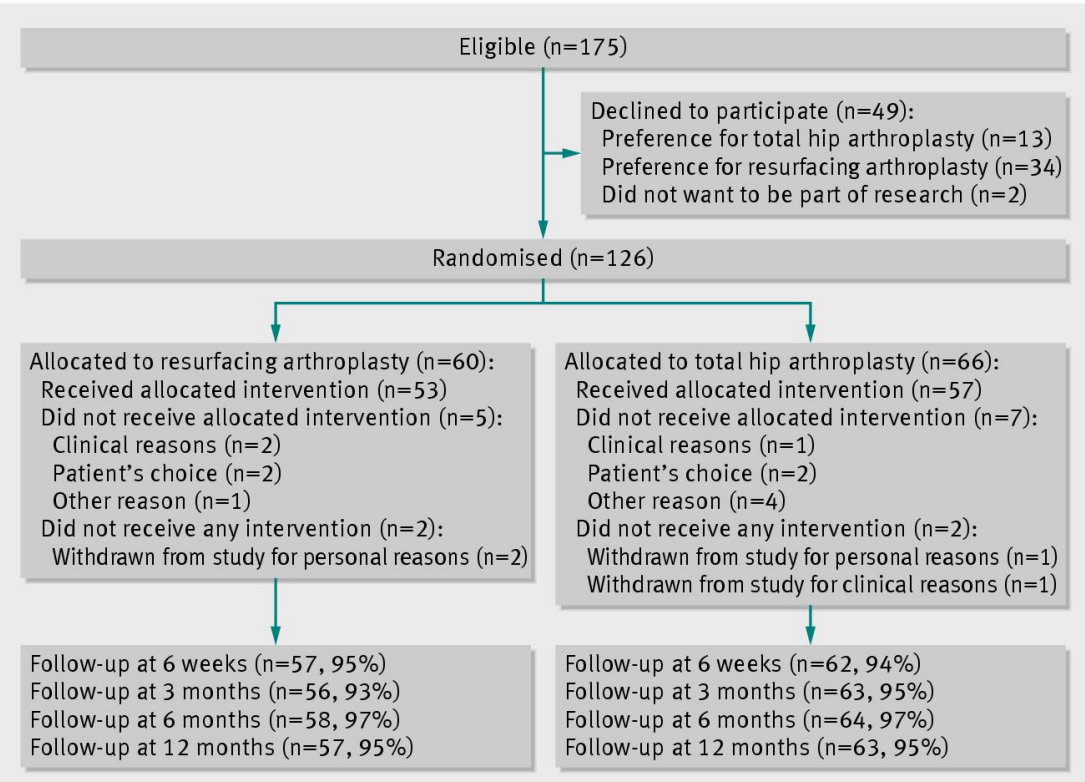

Fig 1 Patient flow diagram
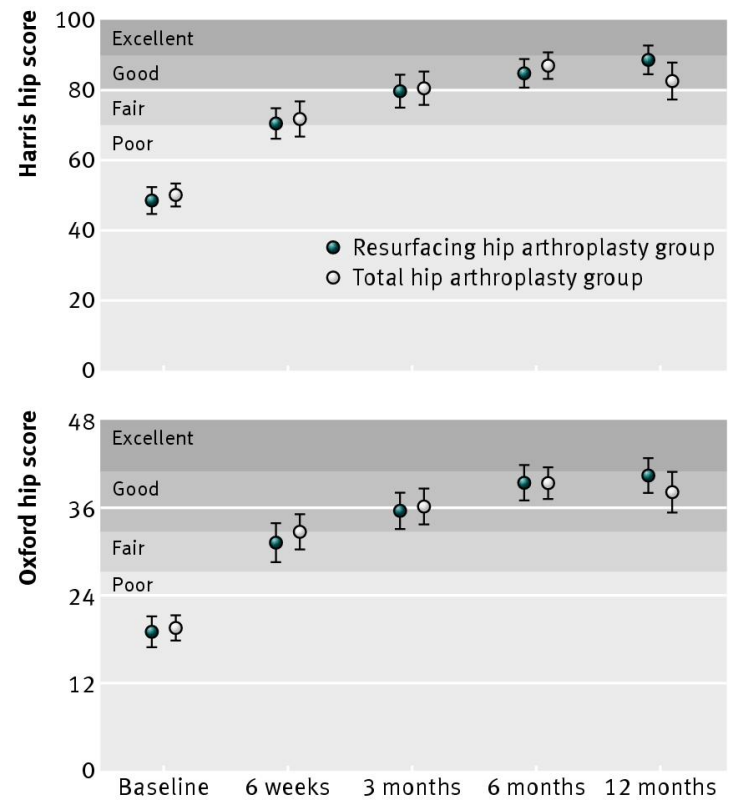

Follow-up

Fig 2 Temporal trends in hip function scores after surgery. ${ }^{31}{ }^{32}$ Data are mean (95\% confidence interval) 